Supporting Information

\title{
Three-Dimensionally Ordered Macroporous Mixed Metal Oxide as an Indicator for Monitoring the Stability of ZIF-8
}

Minog Kim, ${ }^{a}$ Wenyang Zhao, ${ }^{a}$ Michael Tsapatsis,,${ }^{\mathrm{b},}$ and Andreas Stein ${ }^{\mathrm{a}, *}$

${ }^{a}$ Department of Chemistry University of Minnesota, Minneapolis, MN 55455, USA

E-mail:a-stein@umn.edu

${ }^{b}$ Department of Chemical and Biomolecular Engineering \& Institute for NanoBioTechnology,

Johns Hopkins University, MD 21218, USA

E-mail:tsapasis@jhu.edu 

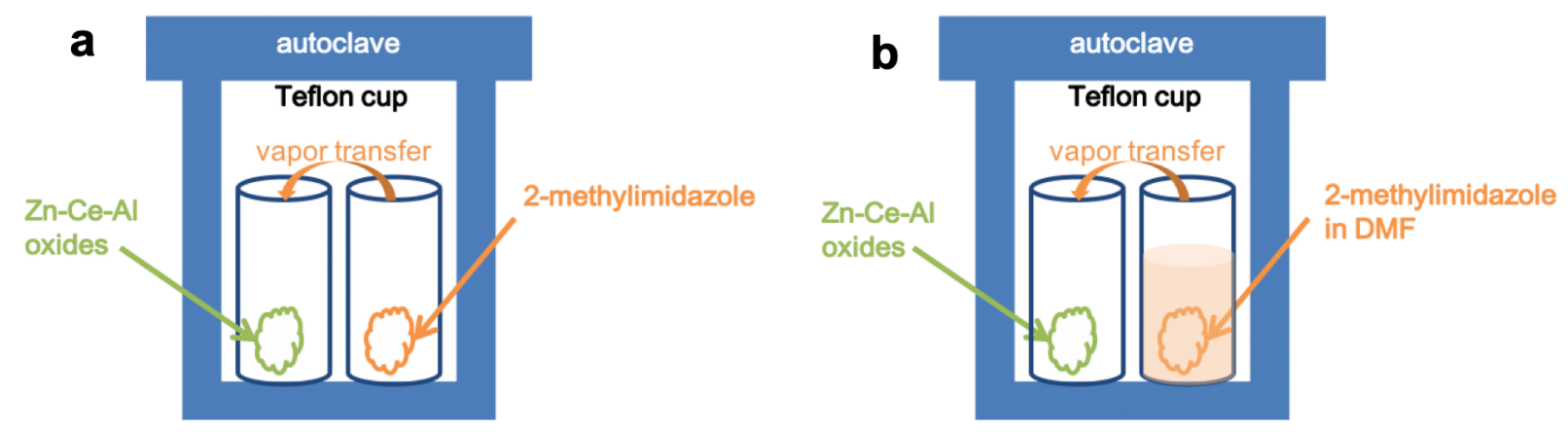

Figure S1. Schematic diagrams of the apparatus used for the synthesis of (a) 3DOM MMO@ZIF-8 and (b) 3DOM $\mathrm{MMO}(80) / \mathrm{ZIF}-8$ from the 3DOM MMO starting material that is labeled as $\mathrm{Zn}-\mathrm{Ce}-\mathrm{Al}$ oxides in this figure. Precursors are separated from each other by placing them in separate glass vials inside Teflon-lined autoclaves.
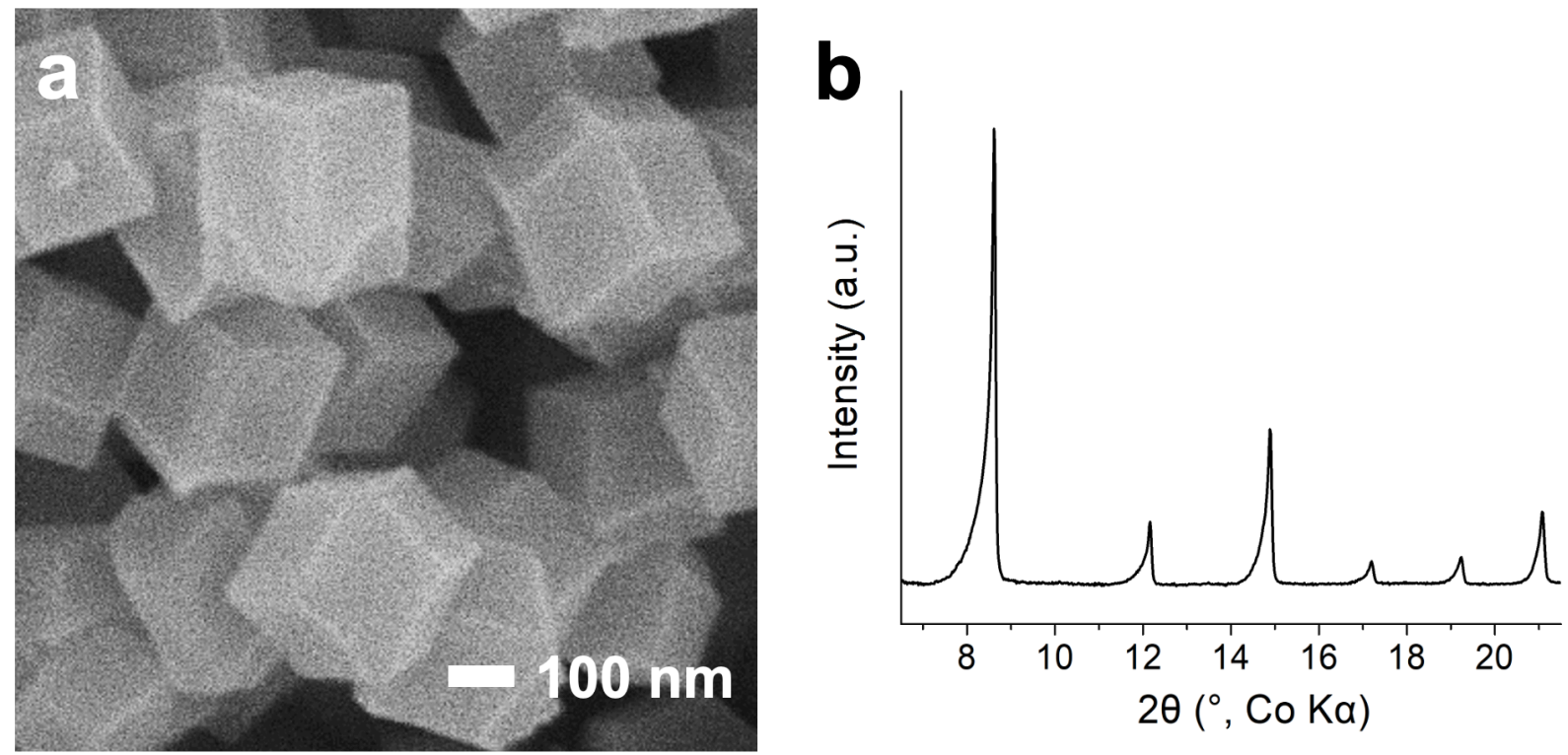

Figure S2. (a) SEM image and (b) XRD pattern of unsupported ZIF-8 particles with a sodalite topology. 


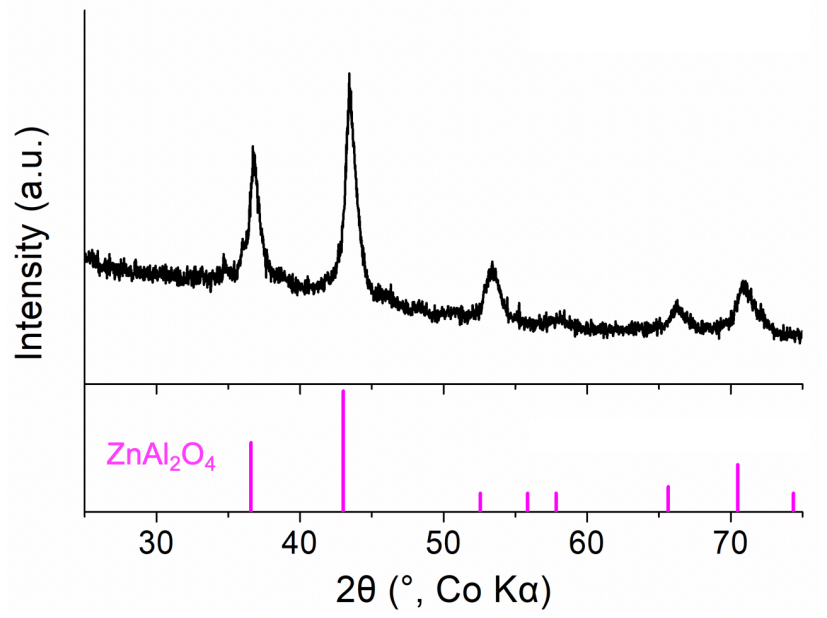

Figure S3. XRD pattern of 3DOM $\mathrm{ZnAl}_{2} \mathrm{O}_{4}$ (black) and line pattern for powder diffraction file (PDF) \#01-1146 $\mathrm{ZnAl}_{2} \mathrm{O}_{4}$, obtained from the International Center for Diffraction Data (ICDD) database (magenta).
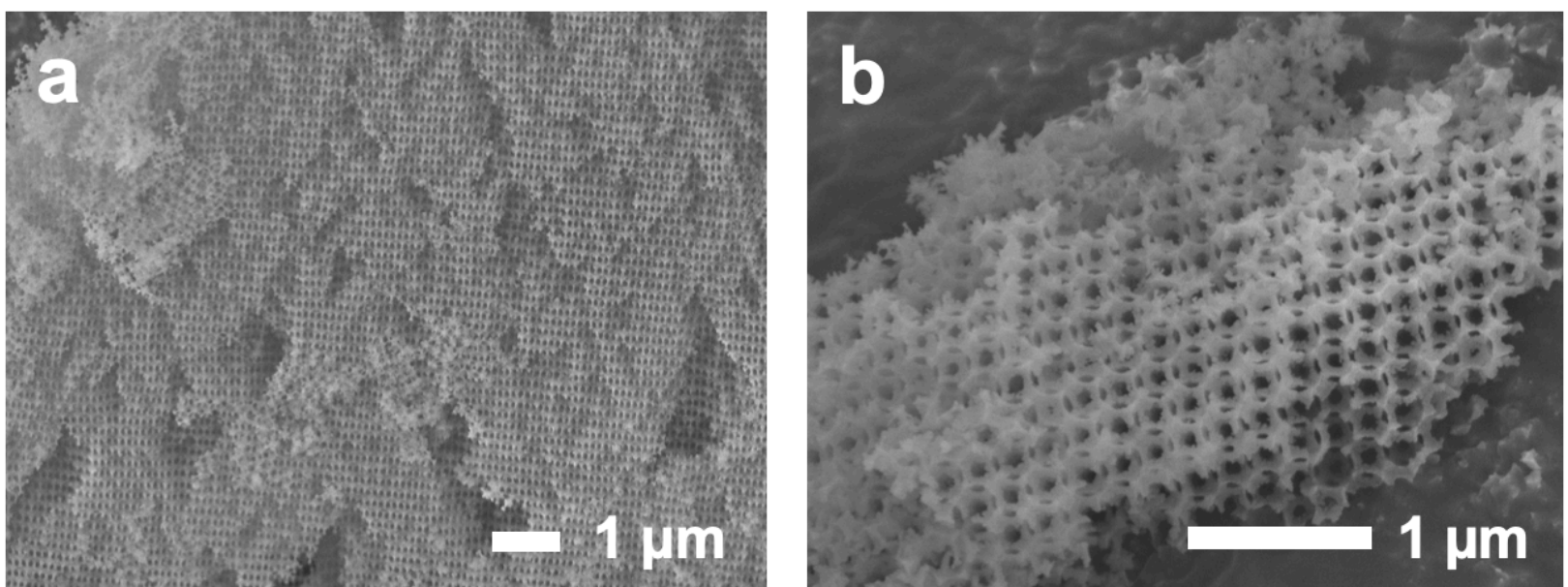

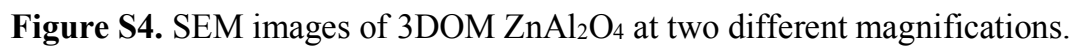



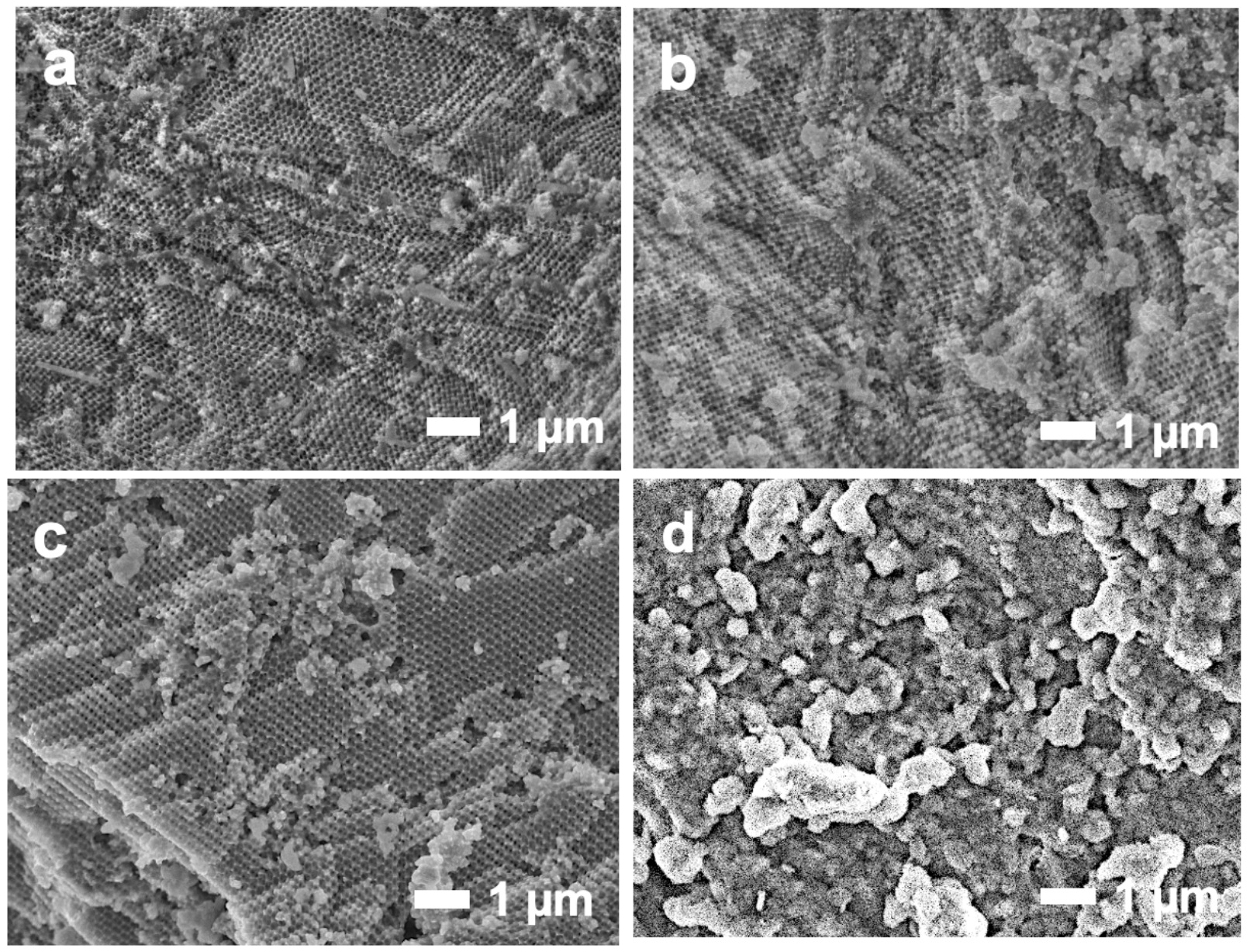

Figure S5. SEM images of 3DOM MMO(80)@ZIF-8, obtained after the following exposure times to Hmim vapor at $130{ }^{\circ} \mathrm{C}$ : (a) $2 \mathrm{~h}$, (b) $3 \mathrm{~h}$, (c) $4 \mathrm{~h}$, and (d) $6 \mathrm{~h}$. The image in (d) shows an external surface. 
C Ka1_2

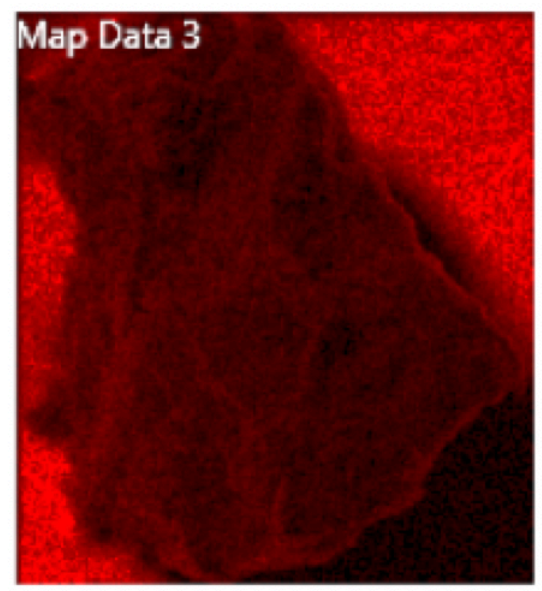

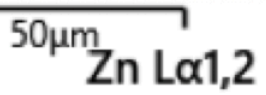

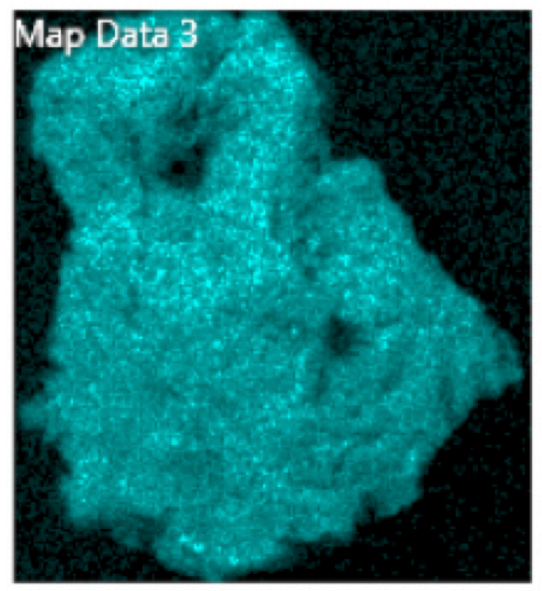

$50 \mu \mathrm{m}$
$\mathrm{O} K \alpha 1$

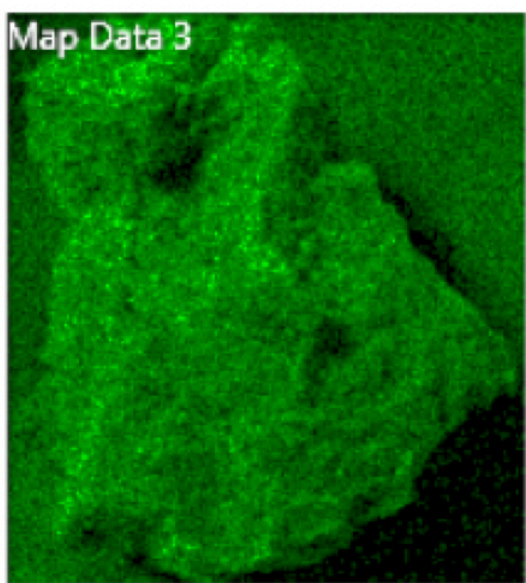

${ }^{50 \mu \mathrm{m}} \mathrm{Ce} \operatorname{L} \alpha 1$

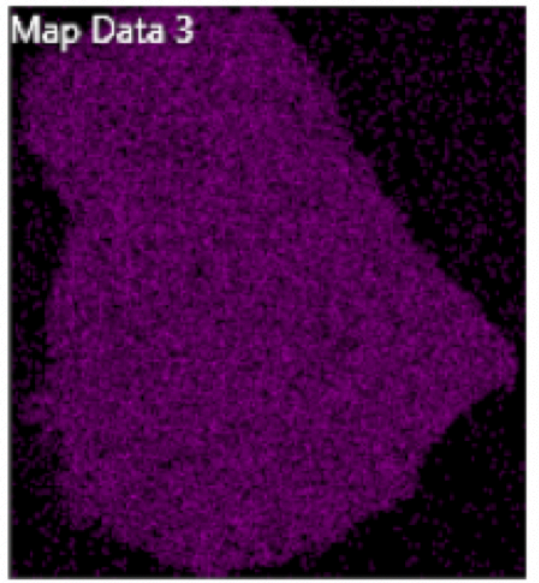

$50 \mu \mathrm{m}$
N K $\alpha 12$

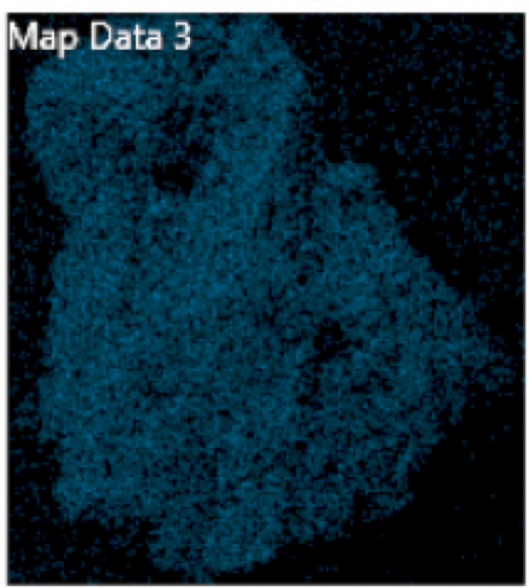

$50 \mu \mathrm{m}$

Al $\mathrm{K} \alpha 1$

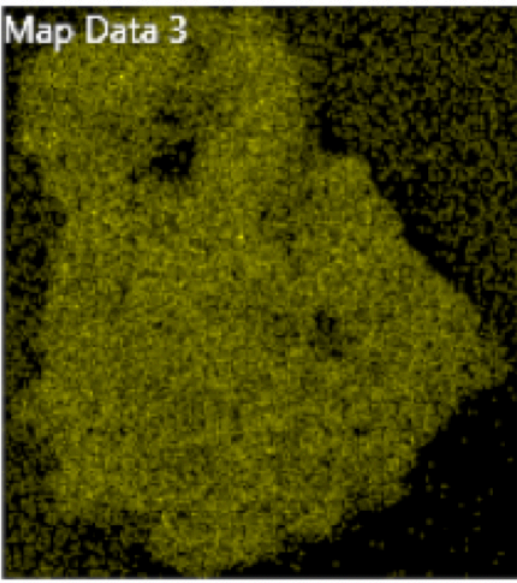

$50 \mu \mathrm{m}$

Figure S6. SEM-EDX maps of 3DOM MMO(80)@ZIF-8 after exposure of 3DOM MMO(80) to Hmim vapor for 4 h. 


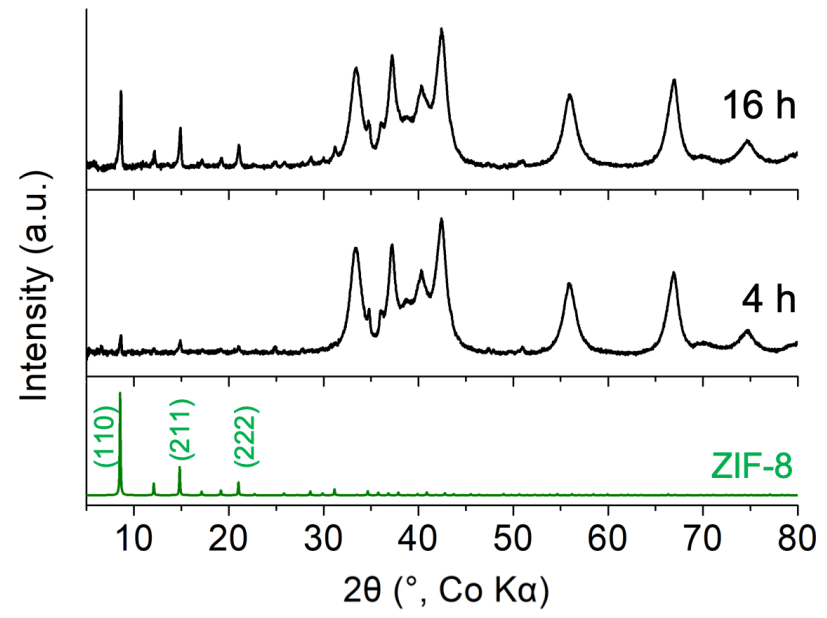

Figure S7. XRD patterns of 3DOM MMO(80)/ZIF-8 samples obtained after exposure of 3DOM MMO(80) to mixed Hmim and DMF vapors for $4 \mathrm{~h}$ and $16 \mathrm{~h}$. 

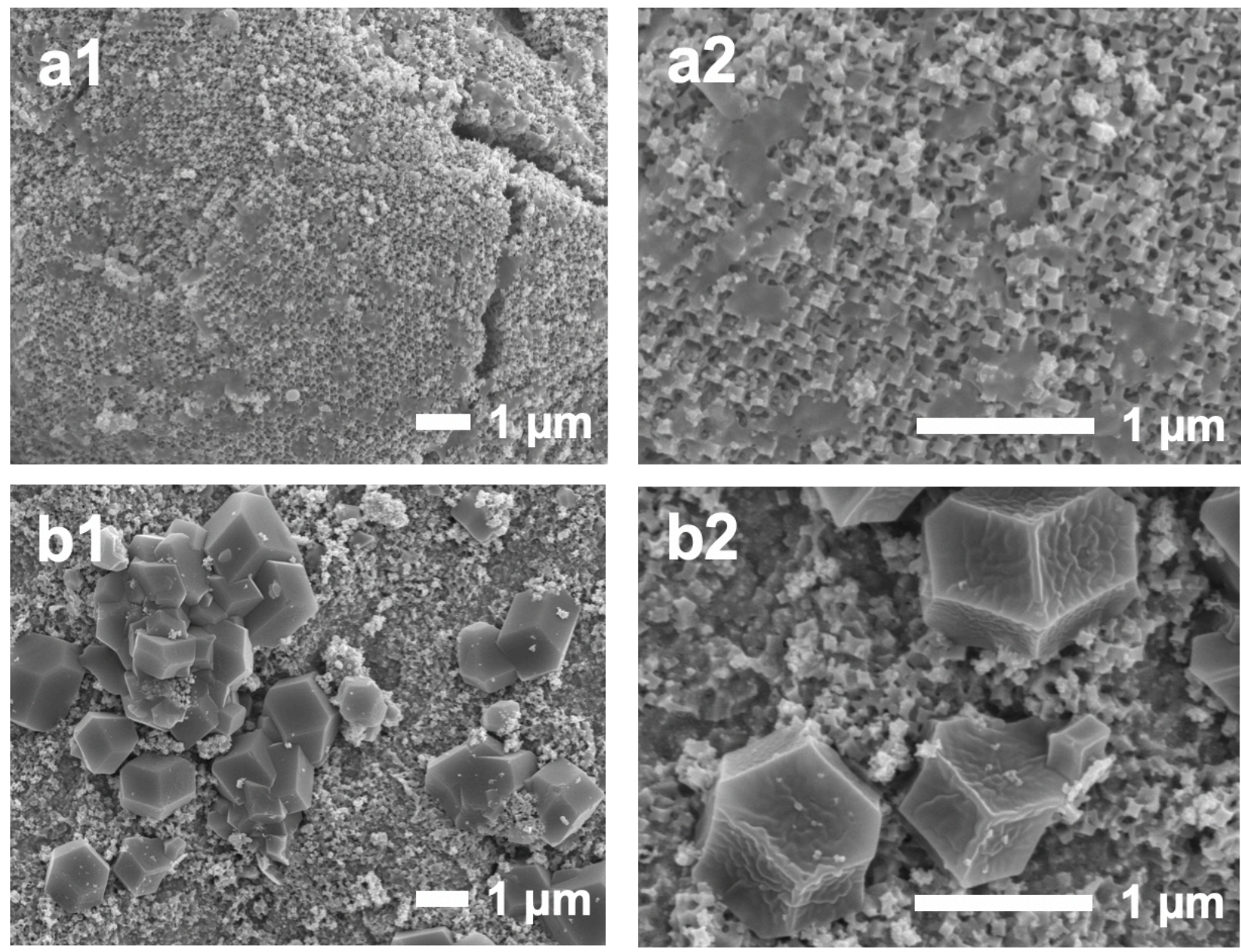

Figure S8. SEM images at two different magnifications of 3DOM MMO(80)/ZIF-8 after exposure of 3DOM $\mathrm{MMO}(80)$ to mixed Hmim and DMF vapors for (a) $4 \mathrm{~h}$ and (b) $16 \mathrm{~h}$.

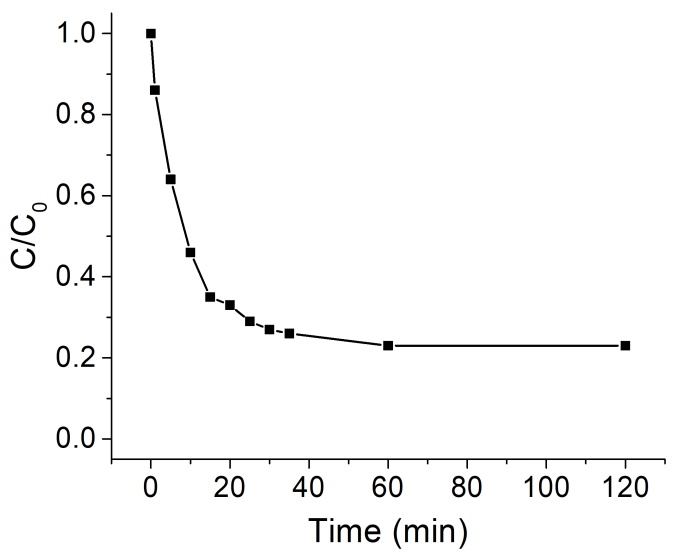

Figure S9. Adsorption of RhB from a 5 ppm aqueous solution by 3DOM MMO(80)@ZIF-8 as a function of time.

This data is derived from UV-vis spectra of the remaining solution at $\lambda_{\max }=554 \mathrm{~nm}$. 
Table S1. Summary of the adsorption capacity of ZIF-8 for RhB in aqueous solution.

\begin{tabular}{|c|c|c|c|c|c|}
\hline $\begin{array}{l}\text { ZIF-8 particle size }(\mathrm{nm}) \text { or } \\
\text { morphology }\end{array}$ & $\begin{array}{l}C_{0} \\
(\mathrm{ppm})\end{array}$ & $\begin{array}{l}\text { amount of } \\
\text { adsorbent and } \\
\text { RhB adsorbate }\end{array}$ & $\begin{array}{l}q_{e} \\
(\mathrm{mg} / \mathrm{g})\end{array}$ & $\begin{array}{l}q_{e} \\
(\mu \mathrm{mol} / \mathrm{g})\end{array}$ & reference \\
\hline 500 & 5 & & 1.4 & 3 & \\
\hline 30 & 5 & $40 \mathrm{mg}+20 \mathrm{~mL}$ & 4.3 & 9 & 1 \\
\hline $30-150$ & 5 & & 4.2 & 9 & \\
\hline $\begin{array}{l}470 \\
300\end{array}$ & $\begin{array}{l}5 \\
5\end{array}$ & $10 \mathrm{mg}+10 \mathrm{~mL}$ & $\begin{array}{l}1.4 \\
4.2\end{array}$ & $\begin{array}{l}3 \\
9\end{array}$ & 2 \\
\hline $\begin{array}{l}2000 \\
50-100\end{array}$ & $\begin{array}{l}50 \\
50\end{array}$ & $10 \mathrm{mg}+10 \mathrm{~mL}$ & $\begin{array}{l}4.1 \\
25\end{array}$ & $\begin{array}{l}9 \\
52\end{array}$ & 3 \\
\hline $\begin{array}{l}3500-4500 \\
500-1500\end{array}$ & $\begin{array}{l}24 \\
24\end{array}$ & $15 \mathrm{mg}+15 \mathrm{~mL}$ & $\begin{array}{l}7.2 \\
20\end{array}$ & $\begin{array}{l}15 \\
42\end{array}$ & 4 \\
\hline 500 & 500 & $20 \mathrm{mg}+40 \mathrm{~mL}$ & 40 & 84 & 5 \\
\hline 200 & $\mathrm{n} / \mathrm{a}$ & $\mathrm{n} / \mathrm{a}$ & 6.4 & 13 & 6 \\
\hline 100 & 13 & $10 \mathrm{mg}+20 \mathrm{~mL}$ & 25 & 52 & 7 \\
\hline unsupported ZIF-8 & 5 & & 3 & 6 & \\
\hline 3DOM MMO(80)@ZIF-8 & & $6 \mathrm{mg}+6 \mathrm{~mL}$ & $12 *$ & $25^{*}$ & this work \\
\hline unsupported ZIF-8 & 50 & & 20 & 42 & \\
\hline 3DOM MMO(80)@ZIF-8 & & & $47 *$ & $97 *$ & \\
\hline
\end{tabular}

*Normalized to the mass of ZIF-8 in the composite. 
Table S2. Summary of the adsorption capacity of various adsorbents for RhB in aqueous solution.

\begin{tabular}{|c|c|c|c|c|}
\hline adsorbent & $\begin{array}{l}\mathrm{C}_{\mathrm{o}} \\
(\mathrm{ppm})\end{array}$ & $\begin{array}{l}\text { time to reach } \\
\text { equilibrium (min) }\end{array}$ & $\begin{array}{l}\mathrm{q}_{\mathrm{e}} \\
(\mathrm{mg} / \mathrm{g})\end{array}$ & reference \\
\hline $\begin{array}{l}\mathrm{Fe}_{3} \mathrm{O}_{4} \text {-based melamine-rich } \\
\text { covalent organic polymer }\end{array}$ & 10 & 4 & 3 & 8 \\
\hline tannic acid functionalized graphene & 16 & 30 & 14 & 9 \\
\hline $\begin{array}{l}\text { multifunctionalized- } \\
\text { superparamagnetic nanoparticles }\end{array}$ & 50 & 15 & 24 & 10 \\
\hline $\begin{array}{l}\text { N-doped hierarchical porous carbon } \\
\text { microspheres }\end{array}$ & 48 & 120 & $\sim 80$ & 11 \\
\hline graphene oxide/polypyrrole & 20 & $\sim 240$ & $\sim 200$ & 12 \\
\hline ZIF-8 & $\mathrm{n} / \mathrm{a}$ & 60 & 38 & 13 \\
\hline $\mathrm{UiO}-66-\mathrm{NH}_{2}$ & $\mathrm{n} / \mathrm{a}$ & 60 & 20 & 13 \\
\hline 3DOM MMO(80)@ZIF-8 & 5 & 30 & $12 *$ & this work \\
\hline 3DOM MMO(80)@ZIF-8 & 50 & 60 & $47 *$ & this work \\
\hline
\end{tabular}

*Normalized to the mass of ZIF-8 in the composite. 


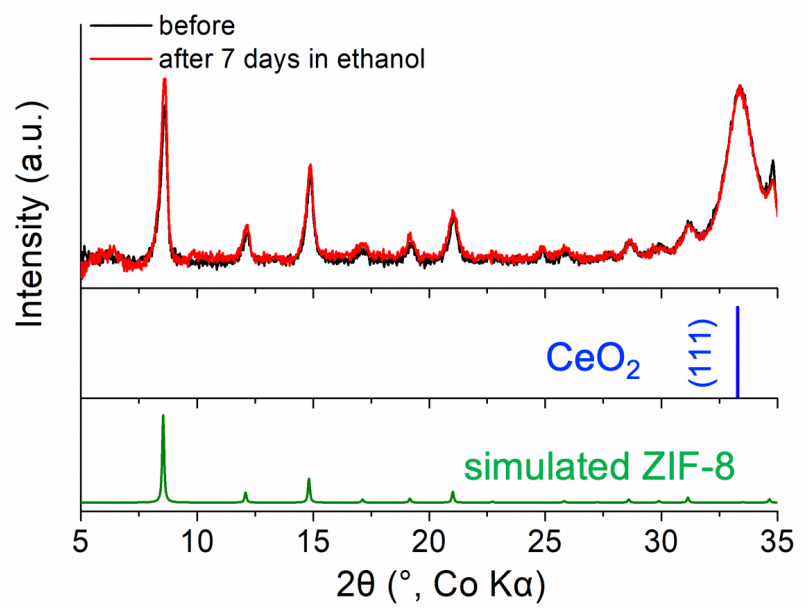

Figure S10. XRD patterns showing the stability of 3DOM MMO(80)@ZIF-8 in ethanol. A mass of 3 mg of 3DOM MMO(80)@ZIF-8 was dispersed in $3 \mathrm{~mL}$ of ethanol, and the mixture was shaken for 7 days. The crystallinity and fraction of ZIF-8 in the composite material did not decrease during this time.

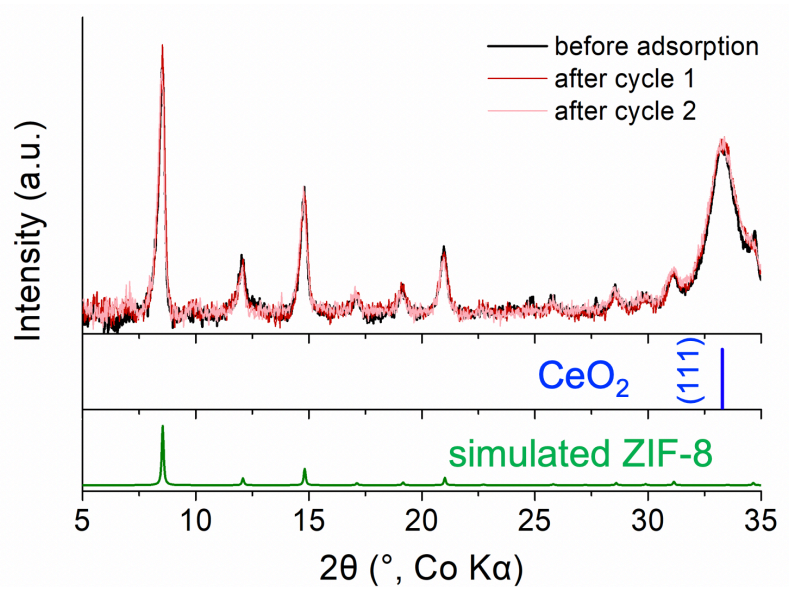

Figure S11. XRD patterns showing the stability of 3DOM MMO(80)@ZIF-8 in an aqueous Rhodamine B solution with an excess of Hmim. The crystallinity and fraction of ZIF-8 in the composite material did not decrease after two cycles of dye adsorption and sorbent regeneration. For this experiment, $3 \mathrm{mg}$ of 3DOM MMO(80)@ZIF-8 were dispersed in $3 \mathrm{~mL}$ of a stock solution containing $0.010 \mathrm{~g} \mathrm{RhB}$ and $1.14 \mathrm{~g} \mathrm{Hmim}$ in $200 \mathrm{~mL}$ of water. The mixture was stirred for $30 \mathrm{~min}$. The adsorbent was then isolated by centrifugation and recycled after washing with ethanol until the supernatant solution was colorless. The same procedure was followed for cycle 2 . 


\section{Mechanical Stability of 3DOM MMO(80)@ZIF-8}

To investigate the mechanical stability of 3DOM MMO(80)@ZIF-8 during stirring operations, as prepared particles were stirred in ethanol for various durations. Figure S12 shows SEM images of 3DOM MMO(80)@ZIF-8 particles as made, after $3 \mathrm{~h}$ of stirring, and after 5 days of stirring. Average particle sizes did not change significantly after $3 \mathrm{~h}$ stirring and the open, periodic 3DOM structure was well maintained. This is consistent with our observation that the adsorption performance of 3DOM MMO(80)@ZIF-8 was maintained for multiple re-use cycles and that the porous solid could be easily recovered after each of those cycles (Figure 7). After 5 days of stirring, the average particles size of 3DOM MMO(80)@ZIF-8 decreased significantly, although numerous larger particles were still present (Figure S12 e, f). However, the 3DOM structure was still maintained and most particles were large enough to recover for additional use. 

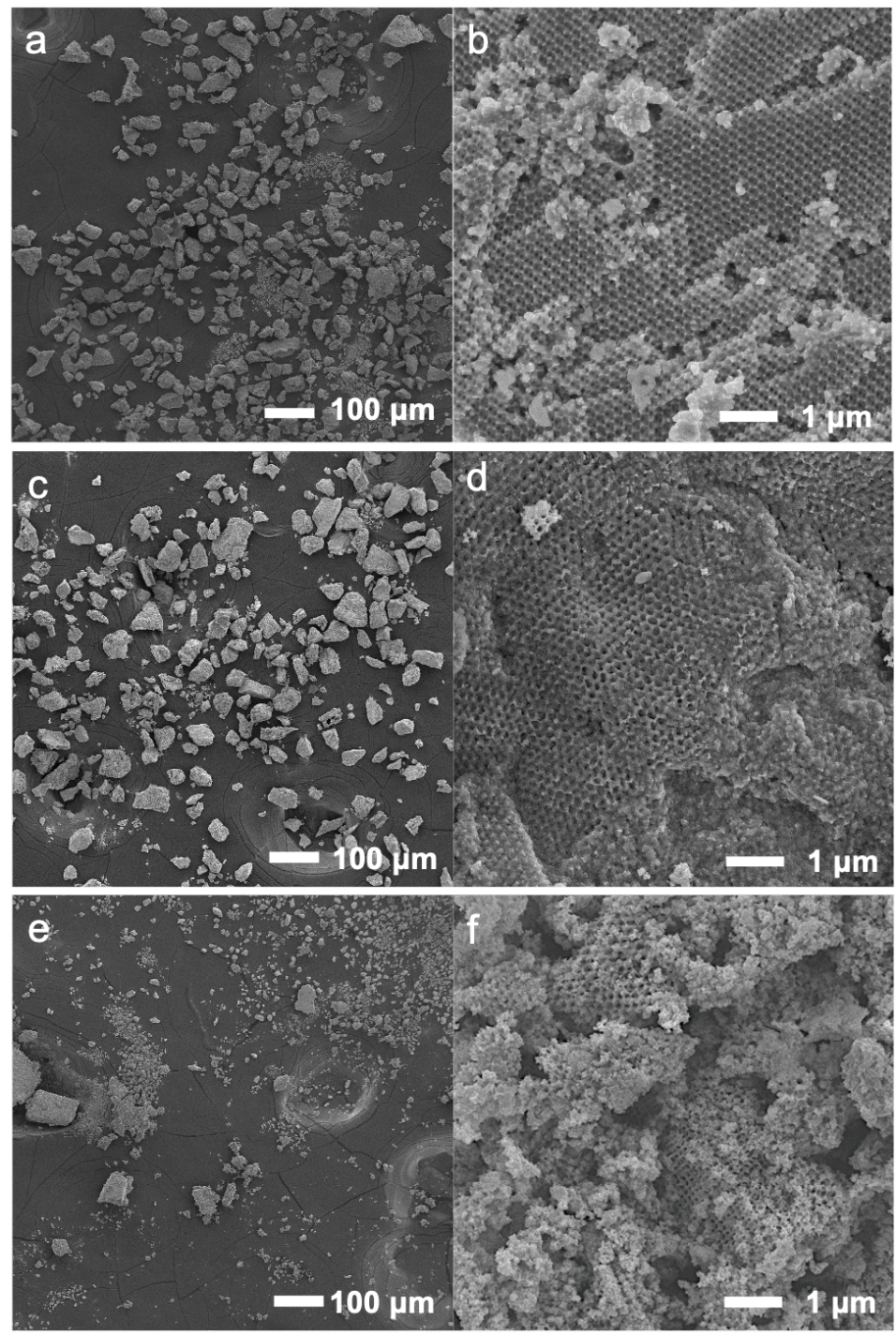

Figure S12. SEM images showing the mechanical stability of 3DOM MMO(80)@ZIF-8 after various times of stirring in ethanol. ( $a, b)$ The original 3DOM MMO(80)@ZIF-8 particles, (c, d) the particles after $3 \mathrm{~h}$ stirring, and (e, f) the particles after 5 days of stirring. 


\section{References}

(1) Tanaka, S.; Kida, K.; Nagaoka, T.; Ota, T.; Miyake, Y. Mechanochemical Dry Conversion of Zinc Oxide to Zeolitic Imidazolate Framework. Chem. Commun. 2013, 49, 7884-7886.

(2) Tanaka, S.; Nagaoka, T.; Yasuyoshi, A.; Hasegawa, Y.; Denayer, J. F. M. Hierarchical Pore Development of ZIF-8 MOF by Simple Salt-Assisted Mechanosynthesis. Cryst. Growth Des. 2018, 18, 274-279.

(3) Tran, B. L.; Chin, H.; Chang, B. K.; Chiang, A. S. T. Dye Adsorption in ZIF-8 : The Importance of External Surface Area. Microporous Mesoporous Mater. 2019, 277, 149153.

(4) Li, Y.; Zhou, K.; He, M.; Yao, J. Synthesis of ZIF-8 and ZIF-67 Using Mixed-Base and Their Dye Adsorption. Microporous Mesoporous Mater. 2016, 234, 287-292.

(5) Feng, Y.; Li, Y.; Xu, M.; Liu, S.; Yao, J. Fast Adsorption of Methyl Blue on Zeolitic Imidazolate Framework-8 and Its Adsorption Mechanism. RSC Adv. 2016, 6, 109608109612.

(6) Li, Z.; Zhou, G.; Dai, H.; Yang, M.; Fu, Y.; Ying, Y.; Li, Y. Biomineralization-Mimetic Preparation of Hybrid Membranes with Ultra-High Loading of Pristine Metal-Organic Frameworks Grown on Silk Nanofibers for Hazard Collection in Water. J. Mater. Chem. A 2018, 6, 3402-3413.

(7) Fan, C.; Liang, Y.; Dong, H.; Yang, J.; Tang, G.; Zhang, W.; Kong, D.; Li, J.; Cao, Y. Guanidinium Ionic Liquid-Controlled Synthesis of Zeolitic Imidazolate Framework for Improving Its Adsorption Property. Sci. Total Environ. 2018, 640, 163-173.

(8) Shakeri, S.; Rafiee, Z.; Dashtian, K. $\mathrm{Fe}_{3} \mathrm{O}_{4}$-Based Melamine-Rich Covalent Organic Polymer for Simultaneous Removal of Auramine O and Rhodamine B. J. Chem. Eng. 
Data 2020, 65, 696-705.

(9) Liu, K.; Li, H.; Wang, Y.; Gou, X.; Duan, Y. Adsorption and Removal of Rhodamine B from Aqueous Solution by Tannic Acid Functionalized Graphene. Colloids Surfaces A Physicochem. Eng. Asp. 2015, 477, 35-41.

(10) Ojemaye, M. O.; Okoh, A. I. Multiple Nitrogen Functionalized Magnetic Nanoparticles as an Efficient Adsorbent: Synthesis, Kinetics, Isotherm and Thermodynamic Studies for the Removal of Rhodamine B from Aqueous Solution. Sci. Rep. 2019, 9, 9672-9684.

(11) Xie, Y.; Yang, W.; Wang, M.; Ge, X. Fibrous N-Doped Hierarchical Porous Carbon Microspheres: Synthesis and Adsorption Performance. Chem. Eng. J. 2017, 323, 224-232.

(12) Yu, H.; Che, M.; Zhao, B.; Lu, Y.; Zhu, S.; Wang, X.; Qin, W.; Huo, M. Enhanced Electrosorption of Rhodamine B over Porous Copper-Nickel Foam Electrodes Modified with Graphene Oxide/Polypyrrole. Synth. Met. 2020, 262, 116332-116341.

(13) Zhang, H.; Shi, X.; Li, J.; Kumar, P.; Liu, B. Selective Dye Adsorption by Zeolitic Imidazolate Framework-8 Loaded UiO-66- $\mathrm{NH}_{2}$. Nanomaterials 2019, 9, 1283-1300. 